\title{
Anti-inflammatory Activity of an Ornamental Plant Plumeria Obtusa
}

\author{
Amogh R. Lotankar ${ }^{1}$, Altamash J. Momin ${ }^{2, *}$, Shaijesh Wankhede ${ }^{3}$, Jyoti B. Sharma ${ }^{4}$ \\ ${ }^{1}$ Executive Medical Affairs, Zifam Pinnacle Pharma, Goregaon, Mumbai, India \\ ${ }^{2}$ Executive Medical Services, Medley Pharmaceuticals, Andheri, Mumbai, India \\ ${ }^{3}$ Advanced Centre for Treatment, Research and Education in Cancer (ACTREC)Kharghar, Navi Mumbai, India \\ ${ }^{4}$ Oriental College of pharmacy, Sanpada, Navi Mumbai, India
}

Copyright $\bigcirc 2016$ by authors, all rights reserved. Authors agree that this article remains permanently open access under the terms of the Creative Commons Attribution License 4.0 International License

\begin{abstract}
Aims: An experiment was conducted to evaluate the anti-inflammatory effects of ethanolic bark extract of Plumeria obtusa. Material and method: Anti-inflammatory activity was evaluated by using two different animal models namely cotton pellet method and carrageenan induce paw edema in male Wistar rats at a dose of 100,200 and $400 \mathrm{mg} / \mathrm{kg}$ respectively. Results: Phytochemical examination of the extract exposed the existence of alkaloids, flavonoids, tannins and terpenoids. The ethanolic extract elicited highly significant $(p<0.001)$ inflammatory activity in a dose dependent manner on cotton pellet method and carrageenan induce paw edema method. This was noticed by prominently decrease of paw volume in carrageenan induce paw edema and marked increase in \% inhibition of cotton pellet Granuloma pouch at the dose of 100,200 and $400 \mathrm{mg} / \mathrm{kg}$ respectively. Conclusion: The present investigations showed that the ethanolic extract Plumeria obtusa stem bark has potential anti-inflammatory activity when screened on carrageenan-induced paw edema and cotton pellet Granuloma pouch models in rats.
\end{abstract}

Keywords Plumeria obtusa, Medicinal Plant, Phytochemical Screening, Anti-inflammatory, Carrageenan, Cotton Pellet

\section{Introduction}

Primary vascular tissue has a complex biological response to harmful stimuli, such as pathogens, damaged cells, or an irritant is known as inflammation. It is a process by which the body's chemicals and white blood cells protect us from infection and foreign substances such as viruses and bacteria. Inflammation is an vital physiological reaction which happens in reaction to an extensive variety of Injurious agents (e.g. bacterial infection or physical trauma) ultimately trying to perform the dual function of promoting tissue repair and limiting damage[1].Inflammation are broadly classified into two types viz; acute inflammation and chronic inflammation. With the dawn of science, traditional system of medicines begins to lose its importance and gradually synthetic drug gained more importance in the present era of allopathic system. Numerous synthetic compounds including Non-steroidal anti-inflammatory drugs (NSAIDs) were presented; but extended use of these anti-inflammatory drugs is associated with side effects. Hence, to explore for nave anti-inflammatory agents that holds the therapeutic efficacy and also lacks the adverse effects associated with it [2].

Plumeria obtusa is a deciduous plant species belonging to the family-Apocynaceae and genus Plumeria usually recognized as Frangipani. Plumeria obtusa is innate to the northern Central America, Greater Antilles, Florida and southern Mexico. Farming is usually done in warmer parts of the world, including Southeast Asia. In traditional medicine, decoction of the bark is used as purgative or as a remedy against edemas. The ethanolic extract of stem bark of Plumeria obtusa exhibited antiulcer effect by ulcer induced pylorus ligation. As per our knowledge, there is scanty scientific report on the confirmation of the use of the stem bark of Plumeria obtusa in inflammation. Hence, the current study was commenced to discover anti-inflammatory prospective of Plumeria obtusa bark in rats so as to validate the traditional uses of this plant in folklore medicine.

\section{Materials and Methods}

\subsection{Collection of Plant Material}

Stem bark of 2-3 years old Plumeria obtusa, common name frangipani, were collected at an altitude of $46 \mathrm{ft}$ in August 2014 from locations of Navi Mumbai, Maharashtra, India and authenticated by Dr. Rajendra D. Shinde, Botanist, Associate Professor at St. Xavier's College, Mumbai-400001. 


\subsection{Extraction \& Phytochemical Evaluation}

The $1 \mathrm{~kg}$ of dried Stem bark of Plumeria obtusa was cleaned by removing contaminated materials, and then were pulverized by an electric blender to give $600 \mathrm{gm}$ of coarsely powder and stored in the airtight container. The coarse powder of stem bark of Plumeria obtusa was extracted with ethanol in Soxhlet extractor. Dark green ethanolic extract was dried under rotary vacuum evaporator, suspended in water and defatted with petroleum ether (thrice) and then successively fractionated in separating funnel with ethyl acetate (thrice) to get hydrophilic fraction (Brown color). Dried ethanolic extract was used further for the study. Further, these extracts were subjected to a battery of phytochemical tests to evaluate the constituents.

\subsection{Animals}

Male Wistar rats, weighing 150-230 g, were used. All animals were procured from Bharat serums and vaccines limited, Thane, India. The animals were kept in the animal room of measured conditions of $24 \pm 1^{\circ} \mathrm{C}$ and $12 \mathrm{~h}$ light -12 $\mathrm{h}$ dark cycles. Food and water were given ad libitum. Animal Ethics Committee had approved all the animal models to be used. \{Protocol number: OCP/IAEC//2014-15/05\}

\subsection{Drugs}

Indomethacin (Donica ${ }^{\circledR} 25 \mathrm{mg}$, IPCA Limited, Mumbai) at dose of $10 \mathrm{mg} / \mathrm{kg}$ was used. Carrageenan was obtained from (S.D. Fine Chemicals, Mumbai, India).

\subsection{Preliminary Phytochemical Screening [3].}

For the confirmation of the presence of the phyto constituents such as alkaloids, glycosides, tannins, steroids, carbohydrate, proteins and amino acids, plant extract was subjected to phytochemical evaluation. Results of phytochemical screening presented in Table 1.

\subsection{Physico-chemical Parameters [4].}

The detection of several physic-chemical parameters such as total ash value, water soluble ash, acid insoluble value, sulphated ash and loss on drying were determined as per World Health Organization (WHO) guidelines for Herbal Formulation and Quality Standardized Herbs [4]. For results of physico-chemical parameters see Table 2.

\subsection{Evaluation of In Vivo Anti-Inflammatory Activity of Stem Bark of Plumeria obtusa}

The extracts were administered by oral gavage where as standard drug was injected Intra-peritoneally. Animals were randomly divided into 5 groups for each model. Each group comprised of 6 rats for the study.

Group I: Control.

Group II: Standard drug (indomethacin, $10 \mathrm{mg} / \mathrm{kg}$ )
Group III: PO (100 mg/kg)

Group IV: PO $(200 \mathrm{mg} / \mathrm{kg})$

Group V: PO (400 mg/kg)

*PO $=$ Stem bark extract of Plumeria obtusa

\subsubsection{Carrageenan-Induced Paw Edema in Rats [5].}

The anti-inflammatory activity of the ethanolic extract of Plumeria obtusa was investigated on carrageenan induced inflammation in rat paw. Half an hour after the administration of the test drugs and standard, $1 \%$ carrageenan was injected to the right hind paw of each animal. The volume of paw edema was measured at $0,1 / 2,1$, 2, 3, 4 and 6 hours using Plethysmometer after administration of carrageenan. The left hind paw served as a reference non-inflamed paw for comparison. The average percent increase in paw volume with time was calculated and compared against the control group.

Table 1. Results of Preliminary Phytochemical test

\begin{tabular}{|c|c|c|c|}
\hline Sr. No. & Phytochemical test & Reagents used & Result \\
\hline \multirow{3}{*}{1} & \multirow{3}{*}{ Alkaloids test } & Mayer's Reagent & + \\
\hline & & Wagner's Reagent & + \\
\hline & & Hager's Reagent & + \\
\hline \multirow{3}{*}{2} & \multirow{3}{*}{ Carbohydrates test } & Molish's Reagent & + \\
\hline & & Benedict's Reagent & + \\
\hline & & Fehling's Reagent & + \\
\hline 3 & Saponin test & Foam Test & + \\
\hline 4 & Glycosides test & $\begin{array}{c}\text { Modified } \\
\text { Brontrager's } \\
\end{array}$ & + \\
\hline 5 & Phytosterol test & Salkowski's Test & + \\
\hline 6 & Fats and Fixed oil test & $\begin{array}{c}\text { Filter Paper press } \\
\text { Test } \\
\end{array}$ & - \\
\hline 7 & Resins test & Acetone Water Test & + \\
\hline 8 & Phenols test & Ferric Chloride Test & + \\
\hline 9 & Tannins test & Gelatin Test & + \\
\hline 10 & Diterpenes test & Copper Acetate Test & + \\
\hline \multirow{4}{*}{11} & \multirow{4}{*}{ Flavonoids test } & $\begin{array}{c}\text { Alkaline Reagent } \\
\text { Test }\end{array}$ & + \\
\hline & & Lead Acetate Test & + \\
\hline & & Shinoda Test & + \\
\hline & & Zinc HCl Test & + \\
\hline 12 & $\begin{array}{c}\text { Proteins and amino } \\
\text { acids test } \\
\end{array}$ & Xanthoproteic Test & + \\
\hline
\end{tabular}

+ Indicates positive

-Indicates negative

\subsubsection{Cotton-Pellet Granuloma Pouch Model [6].}

The animals were administered with vehicle, standard drug and test drugs. One hour after the first dosing, the animals were anesthetized with anesthetic ether and $20 \mathrm{mg}$ of the sterile cotton pellet was inserted one in each groin of rats by making small subcutaneous incision. The incisions were sutured by sterile catgut. After 10 day dosing, the animals were sacrificed by excess anesthesia on $10^{\text {th }}$ day and cotton pellets were removed surgically. Pellets were separated from 
extraneous tissue and dried at $60^{\circ} \mathrm{C}$ until weight become constant. The net dry weight that is after subtracting the initial weight of the cotton pellet was determined. The average weight of the pellet of the control group as well as of the test groups was calculated.

\subsection{Statistical Analysis}

Values are expressed as mean \pm S.D. $(\mathrm{n}=6)$, one way ANOVA followed by Dunnett test; ${ }^{*} \mathrm{P}<0.05,{ }^{* *} \mathrm{P}<0.001$ when compared with the control group.

\section{Result and Discussion}

\subsection{Preliminary Phytochemical Analysis of Plumeria obtusa:}

The preliminary phytochemical examination of Plumeria obtusa fractions revealed the presence of alkaloids, carbohydrates, flavanoids, glycosides, triterpenoids, tannins and phenolic compounds.

\subsection{Physico-chemical Parameters}

Physicochemical parameters of Plumeria obtusa are discovered in accordance with WHO guidelines for Quality Standardized Herbs and Herbal Formulation.

Table 2. Assessment of Physico-chemical parameters

\begin{tabular}{|c|c|}
\hline Parameter & $\% \mathrm{w} / \mathrm{w}$ \\
\hline Total ash & $4.5 \%$ \\
\hline Acid insoluble ash & $1.53 \%$ \\
\hline Water soluble ash & $2.0 \%$ \\
\hline Sulphated ash & $5.6 \%$ \\
\hline Loss on drying & $4.16 \%$ \\
\hline
\end{tabular}

\subsection{Carrageenan Induced Rat Paw Edema}

The carrageenan-induced paw edema model in rats has a direct relation to the cyclooxygenase inhibitors and has been used to investigate the effect of non-steroidal anti-inflammatory agents, which principally prevent the cyclooxygenase involved in prostaglandin synthesis [7].

There was a steady increase in edema paw volume in control group. The treatment group which was pretreated with ethanolic extract of Plumeria obtusa showed inhibition of edema formation in the first and second phase respectively (Fig 1) at a dose of $100 \mathrm{mg} / \mathrm{kg}, 200 \mathrm{mg} / \mathrm{kg}$ and $400 \mathrm{mg} / \mathrm{kg}$. In $1^{\text {st }}$ phase, all doses of Plumeria obtusa showed similar results but, there was increase in inhibition of second phase at higher dose of $400 \mathrm{mg} / \mathrm{kg}$ when compared to the lower doses of $100 \mathrm{mg} / \mathrm{kg}$ and $200 \mathrm{mg} / \mathrm{kg}$ respectively.

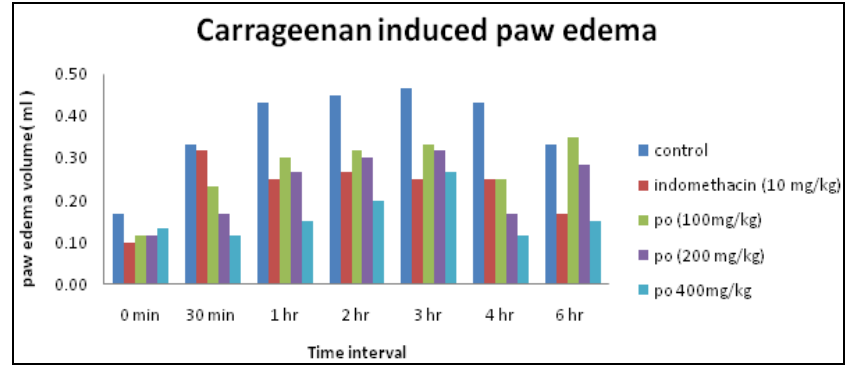

Figure 1. Effect of ethanolic extract of Plumeria obtusa on volume of paw edema.

Statistically significant result was obtained in terms of mean increase in paw volume at a dose of $200 \mathrm{mg} / \mathrm{kg}$ and 400 $\mathrm{mg} / \mathrm{kg}$ in the given interval of time $(30 \mathrm{~min},+1 \mathrm{~h},+2 \mathrm{~h},+3 \mathrm{~h}$, $+4 \mathrm{~h}$, and $+6 \mathrm{~h}$ ).After $+3 \mathrm{~h}$ and $+4 \mathrm{~h}$ of carrageenan administration, Plumeria obtusa exhibited maximum \% inhibition of paw volume $(\mathrm{P}<0.01)$ by $48.45 \%, 60.46 \%$ and $63.61 \%, 72.09 \%$, at the higher two doses of plant extract 200 $\mathrm{mg} / \mathrm{kg}$ and $400 \mathrm{mg} / \mathrm{kg}$ body weight respectively (Fig 2).

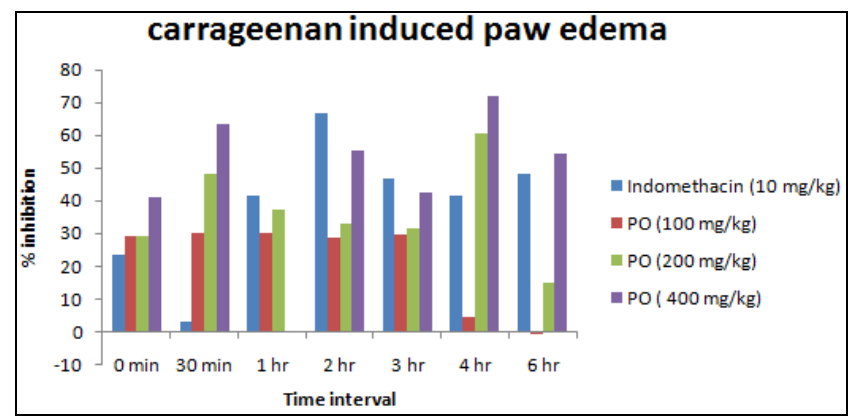

Figure 2. Effect of ethanolic extract of Plumeria obtusa on volume of percent inhibition of paw edema

Extract given at a dose of $100 \mathrm{mg} / \mathrm{kg}, 200 \mathrm{mg} / \mathrm{kg}$ and 400 $\mathrm{mg} / \mathrm{kg}$ significantly inhibited the 2 nd phase paw edema volume induced by carrageenan, this result proposed a mechanism that there might be inhibition of cyclooxygenase synthesis by the extract and this effects are comparable to that created by nonsteroidal anti-inflammatory drugs such as indomethacin, which act in a similar manner by inhibiting cyclooxygenase enzyme.

\subsection{Cotton Pellet Induced Granuloma Pouch Model}

The inflammatory granuloma is associated with chronic inflammatory process [8] [9]. The cotton pellet granuloma method has been extensively used to estimate the exudative, transudative and proliferative components of chronic inflammation [10].

The ethanolic extract of Plumeria obtusa at a dose of 200 $\mathrm{mg} / \mathrm{kg}$ and $400 \mathrm{mg} / \mathrm{kg}$ and standard drug indomethacin showed $(\mathrm{P}<0.001)$ significant activity in inhibiting dry weight of granuloma. The dose administered at $200 \mathrm{mg} / \mathrm{kg}$ and $400 \mathrm{mg} / \mathrm{kg}$ showed a higher anti-granulation $(20.61 \%$ and $33.24 \%$ ) effect respectively but less than indomethacin (31.91\%) (Fig: $3 \&$ 4).Hence, the reduction in the weight of granuloma specifies that the proliferative phase was efficiently repressed by ethanolic extract of Plumeria obtusa. 
Therefore the extract of Plumeria obtusa was found to be effective in cotton pellet induced granuloma pouch model and it can be supposed that it is effective in all the phases of inflammation i.e., acute, sub-acute and proliferative phases. As the action also depends on the pharmacokinetic parameters, the activity of Plumeria obtusa extract was found to decline after $6 \mathrm{hrs}$ indicating that it might be in a phase of metabolism and excretion.

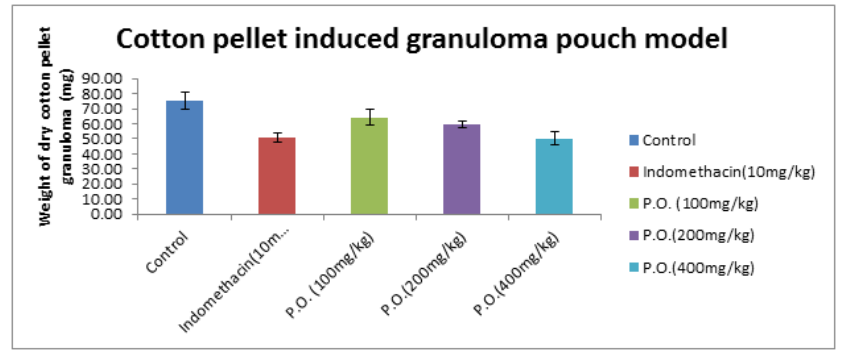

Figure 3. Effect of ethanolic extract of Plumeria obtusa on weight of dry cotton pellets in Cotton pellet induced granuloma pouch model

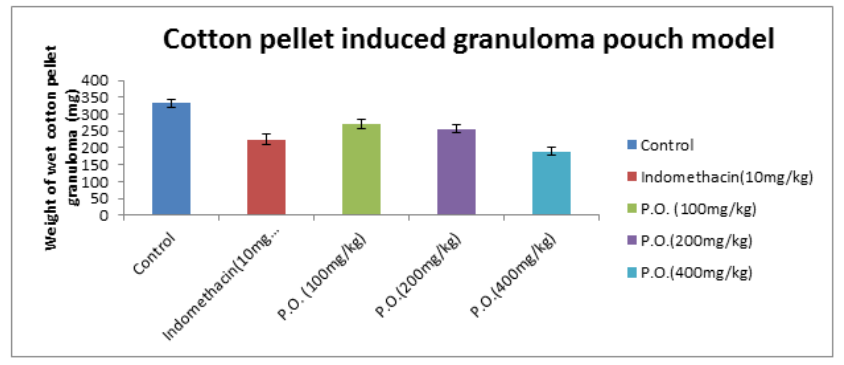

Figure 4. Effect of ethanolic extract of Plumeria obtusa on weight of wet cotton pellets in Cotton pellet induced granuloma pouch model.

\section{Conclusions}

Ethanolic fraction of the stem-bark of Plumeria obtusa exhibited good anti-inflammatory activity when subjected for the screening of the anti-inflammatory activity by using in vivo animal model like carrageenan induced rat paw edema and cotton pellet induced granuloma pouch model. These activities are associated with the presence of glycosides, flavonoids, alkaloids. Plumeria obtusa 400 $\mathrm{mg} / \mathrm{kg}$ showed highly significant result in both in vivo animal models testing, indicating that the effect of the extract was in a dose dependent manner. However, further study is required to determine the actual constituents responsible for anti-inflammatory activity and further authenticate its mechanism of action. A limitation of the study includes that only two experimental models were used. It is a well-known fact that inflammation is often associated with pain. Thus, analgesic activity of the plant Plumeria obtusa needs to be explored. The study holds an advantage that the species of obtusa was used which is commonly used as an ornamental plant whereas other studies have used different species of genus plumeria. This article will be helpful in shedding a light on Plumeria obtusa so that it can be viewed differently; a plant, apart from being so beautiful also possesses healing properties. Future investigating studies are expected to compare the chemical constituents of this plant with available synthetic drugs. As witnessed by history, there are certain plant derived drugs like the anti-malarial drugs such as cinchona alkaloids and arte-ether are more potent and useful. Because of unwanted adverse effects coupled with synthetic drugs, researchers are more enthusiastic to unveil the hidden treasures of the flora world.

\section{Acknowledgements}

We are thankful to our lab assistant Komal Kadam and animal house care taker Arvind Palve for immense corporation and help provided by them.

\section{REFERENCES}

[1] Carl N. Points of control in inflammation. Nature. 2002 Dec 19-26; 420(6917):846-52.

[2] Pan SY, Litscher G, Gao SH, Zhou SF. Historical perspective of traditional indigenous medical practices: the current renaissance and conservation of herbal resources. Evid Based Complement Alternat Med. 2014; 2014:525340.

[3] Kokate CP, Purohit AP, Gokhale SB. (2007), Pharmacognosy, Nirali Prakashan.; 39th edition: 607-611.

[4] Dr. Khandelwal KR. Practical Pharmacognosy Techniques and Experiments. Nirali Prakashan; Content-23; Pageno-23.1-23.7.

[5] Amdekar S, Roy P, Singh V, Kumar A, Singh R, Sharma P. Anti-inflammatory activity of lactobacillus on carrageenan-induced paw edema in male wistar rats. Int $\mathbf{J}$ Inflam. 2012; 2012:752015.

[6] Eddouks M, Chattopadhyay D, Zeggwagh NA. Animal models as tools to investigate antidiabetic and anti-inflammatory plants. Evid Based Complement Alternat Med. 2012;2012:142087

[7] Rachh MA, Yadav PN, Gokani RH and Jain SM. Anti-inflammatory activity of benincasa hispida fruit. Int $\mathrm{J}$ Pharm. Bio. Sci.2011;2011:99-106

[8] Saleem M, Akhtar N, Riaz N, Ali MS, Jabbar A. Isolation and characterization of secondary metabolites from Plumeria obtusa. J Asian Nat Prod Res. 2011 Dec; 13(12): 1122-7.

[9] Aidroos MH, Joshi BC, Dobhal MP and Sharma MC. A Brief Review on Chemical Constituents of Some Medicinally Important Species of the Genus Plumeria. Asian J. Chem.1997;9(4): 571-578

[10] Amit PS, Vaibhav S, Piuesh K. Effects of Plumeria obtusa linn. In peptic ulcer induced by pylorus ligation \& indomethacin. JPSI 1 (2), April 2012, 26-32 